\title{
Trabalho e literatura: o perfil de um grupo de escritores brasileiros
}

\author{
Ana Luíza S. V. Lopes ${ }^{1}$ \\ Cristina Lyra Couto de Souza ${ }^{2}$
}

Resumo: A crescente importância econômica e social das indústrias criativas - atividades que abrangem toda a produção cultural ou artística - ainda não se refletiu na geração de estudos sobre suas questões gerenciais e organizacionais. Nesse contexto, as autoras deste artigo têm se empenhado em pesquisar a produção nas indústrias criativas a partir da perspectiva de seus principais atores - os criadores e os gestores - procurando saber como trabalham, o que desejam, como interagem e que dificuldades enfrentam. $O$ presente estudo faz parte dessa linha investigativa e teve como objetivo descrever o perfil de escritores brasileiros. Foram realizadas uma revisão de literatura em Administração e uma pesquisa qualitativa, na linha construtivista, baseada em entrevistas em profundidade com escritores atuantes no mercado. Os resultados da pesquisa sugerem que: apesar de a formação acadêmica específica na área de atuação não ser necessária para o exercício da profissão, os entrevistados valorizam o estudo e atualização constante; muitos exercem atividades paralelas ao trabalho artístico - necessárias ao sustento - mas, se fosse possível, prefeririam viver apenas da literatura, mesmo obtendo menor remuneração; a necessidade de publicação vai além da expectativa de retorno financeiro: ela é vista como a conclusão do trabalho, independentemente do resultado das vendas; concluindo, os escritores possuem uma motivação intrínseca ligada ao exercício da atividade artística em si - para muitos, além do prazer gerado pelo ato, essa expressão é uma necessidade que, não atendida, gera cansaço e desânimo.

Palavras-chave: Escritores. Trabalho artístico. Trabalho criativo. Indústrias criativas. Administração.

\section{Introdução}

Diante das mudanças ocorridas, a partir da década de 1960, na economia, na produção e na organização do trabalho (HARVEY, 1992), uma das áreas que vêm se transformando bastante é o setor cultural (FLEW; CUNNINGHAM, 2010). As atividades ligadas à arte e à cultura vêm assumindo posições de destaque, não apenas nas discussões sobre preservação da

\footnotetext{
${ }^{1}$ Ana Luiza S. V. Lopes é doutora em Administração pelo COPPEAD-UFRJ e mestre em Administração pela PUC-Rio. Atualmente dedica-se à pesquisa de temas como autonomia e criatividade no trabalho, relações de trabalho e novas formas de gestão. Publicou trabalhos acadêmicos sobre contrato psicológico, profissionais maduros e cultura organizacional, tendo interesse pela área de Literatura. E-mail: analuizasvlopes@gmail.com.

${ }^{2}$ Cristina Lyra Couto de Souza é doutora e mestre em Administração pelo PUC-Rio. Atualmente dedica-se à pesquisa de temas como autonomia e criatividade no trabalho, indústria criativa em diversas áreas e novas formas de gestão. E-mail: crislyra@gmail.com.
} 
$\begin{array}{llllllll}R & \text { E } & \text { V } & \text { I } & \text { S } & \text { T } & \text { A } & \text { N. 24-2012.2-ANA LUIZA S.V LOPES }\end{array}$

identidade e manutenção da diversidade cultural em um cenário de globalização, mas também no papel que desempenham no cenário econômico.

Segundo Potts e Cunningham (2010), a constatação básica de estudos realizados na Austrália, Estados Unidos, Grã-Bretanha e União Europeia, no período de 1999 a 2006, foi de que as indústrias criativas - atividades nas quais a criatividade é a essência do negócio, abrangendo toda a produção cultural ou artística - estão crescendo a uma taxa maior do que o restante da economia. Para esses autores, essas indústrias contribuem para o processo de crescimento econômico, além de sua contribuição para a cultura e a sociedade.

Tepper (2002) aponta que os recursos criativos vêm sendo anunciados como motores de desenvolvimento e crescimento econômico. O termo recursos criativos engloba tanto os bens e serviços que são os produtos principais de um ato expressivo - literatura, música, pintura, teatro, dança etc. - quanto os trabalhadores que os produzem. Tepper destaca que, mais importante do que gastar tempo calculando o impacto ou o tamanho da economia criativa, é dirigir as energias para se compreender melhor como o trabalho e as instituições criativas estão mudando e o que pode ser feito para promover a diversidade e a criatividade.

Lampel et al. (2009) reforçam que, apesar de sua significância econômica e produtiva, o setor cultural não tem recebido muita atenção dos pesquisadores de gestão, havendo poucos estudos empíricos e uma quantidade ainda menor de estudos abordando as questões gerenciais e organizacionais do setor. Para os autores, a base da explicação para essa omissão está na forma como os acadêmicos veem as indústrias culturais: as visões predominantes sobre gestão estão frequentemente em desacordo com as práticas gerenciais e os padrões organizacionais observados nesses tipos de empreendimento.

Bendassolli et al. (2009) também apontam a necessidade de investigações concentradas no trabalho do artista ou do indivíduo criativo e mais pesquisas empíricas, do tipo grounded research, avaliando aspectos variados de gestão nas indústrias criativas. Townley, Beech e McKinlay (2009) destacam a necessidade do desenvolvimento de uma forma diferente de gestão para esse tipo de atividade.

Considerando a crescente relevância cultural e econômica das atividades criativas e a ausência de estudos sobre as questões gerenciais e organizacionais deste tipo de negócio, as autoras deste trabalho têm se empenhado em pesquisar sobre a produção nas indústrias criativas a partir da perspectiva de seus principais atores - os criadores e os gestores -, 
procurando saber como trabalham, o que desejam, como interagem e que dificuldades enfrentam. O presente estudo faz parte dessa linha investigativa e tem como objetivo descrever o perfil de um grupo de escritores brasileiros diante das questões aqui levantadas.

\section{Os criadores e o trabalho nas indústrias criativas: uma breve revisão da literatura em Administração}

Nas indústrias criativas, a criatividade é a essência do negócio e são os trabalhadores criativos que dão origem à concepção e desenvolvimento dos produtos. Logo, os criadores são a matéria-prima da economia criativa e, portanto, para entender o setor é fundamental conhecer esses indivíduos. Os escritores, foco de interesse deste artigo, representam um tipo específico de trabalhador criativo: o artista ou trabalhador cultural.

Todos os produtos do trabalho humano são significativos, porém a maioria é fabricada principalmente por razões instrumentais, como alimentação, vestuário e transporte. $\mathrm{O}$ trabalho cultural, no entanto, é um tipo especial de trabalho criativo na medida em que trata da comunicação de sentido e, muitas vezes, também, de identificação e prazer (McGUIGAN, 2010). McGuigan (2010) destaca ainda que a motivação para o trabalho cultural é geralmente ligada a uma expectativa favorável de ligação da concepção e execução, representando a realização de um trabalho não alienado.

Menger (2010) destaca que o estudo das profissões artísticas apresenta um problema incomum: a dificuldade de sua definição. Nas artes, as diferenças em termos de reputação e ganhos são substanciais, e a correlação entre os níveis de educação, de reputação e de rendimentos é inferior a de outras profissões. Daí o surgimento de uma pluralidade de critérios que visam reconhecer a legitimidade da profissão artística. Menger (2010) destaca que o reconhecimento dessa pluralidade levou os economistas Bruno Frey e Werner Pommerehne a proporem pelo menos oito critérios para definir o artista: (1) tempo dedicado ao trabalho artístico; (2) importância da renda da atividade artística; (3) ser considerado como artista pelo público; (4) ser reconhecido como artista pelos outros artistas; (5) qualidade dos trabalhos artísticos produzidos - o que implica que o conceito de qualidade deve ser definido; (6) pertencimento a um grupo ou associação de artistas profissionais; (7) qualificação profissional (diplomas de escolas de arte); (8) e resposta pessoal de cada um à pergunta: "Sou um artista?". 
Para Menger (2010), o artista é uma pessoa que cria, ou contribui, com sua interpretação, para a criação ou recriação de obras; que considera a sua criação artística como elemento essencial de sua vida; que contribui para o desenvolvimento da arte e da cultura; e é reconhecido ou pretende ser reconhecido como um artista, sendo relacionado ou não a uma relação de emprego ou associação. $\mathrm{O}$ autor destaca que o exercício profissional de uma atividade artística busca, sobretudo, uma recompensa não financeira, uma satisfação intrínseca, o que seria a condição da criatividade genuína.

Entretanto, isso não significa que a remuneração não desempenha papel algum: muitos artistas rejeitam a imagem de indiferença em relação ao dinheiro (GREFFE, 2010). Thorsby (2007) destaca que é muito comum que as escolhas profissionais dos artistas envolvam uma decisão importante sobre como dividir o tempo total de trabalho entre três alternativas: trabalho criativo, trabalho ligado às artes e trabalho não-artístico. As decisões quanto à alocação do tempo são motivadas pelo desejo de engajamento artístico e mediadas por limitações financeiras.

Em um estudo sobre a identidade dos profissionais criativos, Elsbach (2009) identifica algumas categorias importantes, entre elas:

- Indivíduo idealista - artistas profissionais comumente relatam que a satisfação pessoal, intelectual e estética que ganham com a criação é a motivação mais importante para o seu trabalho, enquanto atender às necessidades práticas, como a satisfação de um cliente ou pagar as contas, é uma questão secundária.

- Profissional "show-er" - artistas profissionais veem a exposição de seu trabalho, por exemplo, em galerias, como uma dimensão essencial de sua identidade, pois é a demonstração de que sua arte é legítima e valorizada pela sociedade em geral.

Em outro estudo recente, Hesmondhalgh e Baker (2010) relatam que uma série de pesquisas sobre o trabalho artístico tem gerado resultados claros: há predominância de trabalhadores independentes ou autônomos; os artistas tendem a se dividir em vários trabalhos; o trabalho é irregular - com contratos de curto prazo ou pouca garantia no emprego; as perspectivas de carreira são incertas; os ganhos são muito desiguais; os artistas são mais jovens do que os outros trabalhadores; e a força de trabalho parece estar crescendo. 
É importante destacar, ainda, que os escritores atuam mais como pequenas empresas do que como empregados, pois raramente trabalham por salários. Os contratos para o fornecimento de seus serviços são geralmente formulados em termos do produto final - um livro, uma pintura, uma escultura - e não do número de horas trabalhadas.

\section{Metodologia}

Com base na crença de que o conhecimento é uma construção humana e não uma verdade absoluta e imutável, a linha filosófica seguida pela pesquisa foi a construtivista (GUBA, 1990). Nessa linha, as descobertas surgem a partir da interação entre o pesquisador e o pesquisado (CRESWELL, 2003) e, portanto, foi realizada uma pesquisa qualitativa, com entrevistas em profundidade.

Foram selecionados para participar da pesquisa escritores de ficção com ao menos três obras publicadas. ${ }^{3}$ Essa restrição foi necessária para diferenciar os indivíduos que atuam no mercado, de outros que escrevem apenas por hobby. O Quadro 1 apresenta uma breve descrição dos entrevistados.

\section{Quadro 1: Breve descrição dos entrevistados}

\begin{tabular}{|l|l|l|l|}
\hline & Atividade artística & Ocupação principal & Obras publicadas \\
\hline $\begin{array}{l}\text { Caio } \\
42 \text { anos }\end{array}$ & Romancista e contista & $\begin{array}{l}\text { Roteirista de televisão, com } \\
\text { vínculo empregatício }\end{array}$ & $\begin{array}{l}\text { 3 romances e participação em } \\
\text { antologias de contos }\end{array}$ \\
\hline $\begin{array}{l}\text { Ivan } \\
56 \text { anos }\end{array}$ & Romancista & $\begin{array}{l}\text { Presidente de criação de } \\
\text { uma agência mundial de } \\
\text { publicidade }\end{array}$ & $\begin{array}{l}\text { 1 livro de publicidade e 2 } \\
\text { romances }\end{array}$ \\
\hline $\begin{array}{l}\text { Igor } \\
39 \text { anos }\end{array}$ & Contista & $\begin{array}{l}\text { Editor de conteúdo de } \\
\text { publicações impressas e } \\
\text { virtuais, vínculo } \\
\text { empregatício }\end{array}$ & $\begin{array}{l}\text { 2 livros de contos, participação } \\
\text { em antologias, textos ficcionais } \\
\text { veiculados em revistas de } \\
\text { cultura }\end{array}$ \\
\hline $\begin{array}{l}\text { Sofia } \\
59 \text { anos }\end{array}$ & $\begin{array}{l}\text { Contista, romancista e } \\
\text { cronista }\end{array}$ & $\begin{array}{l}\text { Escreve e organiza } \\
\text { antologias }\end{array}$ & $\begin{array}{l}\text { 3 romances, 1 novela, 1 livro de } \\
\text { memórias, 6 de contos, 1 infantil } \\
\text { e participação em antologias }\end{array}$ \\
\hline
\end{tabular}

${ }^{3}$ Os nomes dos escritores são fictícios, para que sua privacidade seja preservada. Conforme mencionado na metodologia, Na metodologia, lembremos, explicamos que "foram selecionados para participar da pesquisa escritores de ficção com ao menos três obras publicadas. Essa restrição foi necessária para diferenciar os indivíduos que atuam no mercado, de outros que escrevem apenas por hobby". A partir deste critério, entrevistamos os que aceitaram participar da pesquisa. É importante esclarecer ainda que, de um grupo maior de artistas entrevistados, com diferentes atuações (artistas plásticos, atores, cantores), os citados no artigo foram os únicos escritores participantes da pesquisa. 
$\begin{array}{llllllll}\mathbf{R} & \mathbf{E} & \mathbf{V} & \mathbf{I} & \mathbf{S} & \mathbf{T} & \mathbf{A} & \text { N. 24-2012.2-ANA LUIZA S.V LOPES }\end{array}$

CRISTINA LYRA COUTO DE SOUZA

\begin{tabular}{|l|l|l|l|}
\hline $\begin{array}{l}\text { José } \\
70 \text { anos }\end{array}$ & $\begin{array}{l}\text { Romancista, contista e } \\
\text { cronista }\end{array}$ & Escreve e ministra palestras & $\begin{array}{l}\text { 1 livro de contos, 1 de crônicas, } \\
1 \text { infantil, 2 projetos especiais e } \\
11 \text { romances, traduzidos e } \\
\text { publicados em diversos países }\end{array}$ \\
\hline $\begin{array}{l}\text { Artur } \\
66 \text { anos }\end{array}$ & $\begin{array}{l}\text { Romancista, ensaísta, } \\
\text { contista, cronista, } \\
\text { dramaturgo e roteirista }\end{array}$ & $\begin{array}{l}\text { É cronista de jornal e atua } \\
\text { em diversas áreas da vida } \\
\text { cultural como } \\
\text { conferencista, curador e } \\
\text { articulista }\end{array}$ & $\begin{array}{l}\text { romances, 1 livro infantil, 3 de } \\
\text { contos e crônicas, 15 peças de } \\
\text { teatro, várias telenovelas e } \\
\text { minisséries para TV e 15 } \\
\text { roteiros cinematográficos }\end{array}$ \\
\hline $\begin{array}{l}\text { Lucas } \\
50 \text { anos }\end{array}$ & $\begin{array}{l}\text { Romancista, poeta, } \\
\text { contista e ensaísta }\end{array}$ & $\begin{array}{l}\text { Escreve, ministra cursos e } \\
\text { palestras, organiza } \\
\text { antologias }\end{array}$ & $\begin{array}{l}\text { 2 livros de contos, 1 de poemas, } \\
\text { romances e 1 ensaio, } \\
\text { participação em antologias, } \\
\text { vários livros traduzidos e } \\
\text { publicados no exterior }\end{array}$ \\
\hline $\begin{array}{l}\text { Diogo } \\
43 \text { anos }\end{array}$ & $\begin{array}{l}\text { Escritor e ilustrador de } \\
\text { livros }\end{array}$ & $\begin{array}{l}\text { Elabora projetos editoriais e } \\
\text { realiza palestras, cursos e } \\
\text { workshops }\end{array}$ & $\begin{array}{l}\text { Trabalhos publicados em } \\
\text { revistas, livros e jornais } \\
\text { (nacionais e internacionais) }\end{array}$ \\
\hline
\end{tabular}

Todas as conversas - com duração de cerca de uma hora e meia cada - foram gravadas praticamente na íntegra, com o consentimento dos participantes, e posteriormente transcritas de forma minuciosa, para facilitar a interpretação.

A complexidade e a subjetividade dos dados exigiu a utilização de um método que possibilitasse sua compreensão e tradução. Portanto, utilizou-se a análise de conteúdo - um conjunto de técnicas que visa, por meio de procedimentos sistemáticos e objetivos de descrição do conteúdo das mensagens, obter indicadores, quantitativos ou não, que permitam a inferência de conhecimentos relativos às condições de produção e recepção dessas mensagens (BARDIN, 2004).

De acordo com Bardin (2004), a organização da análise é feita em torno de três polos cronológicos: (1) Pré-análise - organização do material coletado para efeito de observação e comparação das mensagens; (2) Descrição analítica - relato do conteúdo das respostas dos entrevistados que exemplificam a análise do material coletado, incluindo citações literais das falas dos sujeitos. Nessa etapa é realizada uma categorização dos dados coletados, com o objetivo de encontrar ideias convergentes e divergentes. O software Atlas ti foi utilizado para auxiliar na criação das categorias e classificação das citações; (3) Interpretação referencial interpretação dos conceitos emergentes das entrevistas, tendo como referencial os enfoques teóricos revistos na literatura. 


\section{Resultados}

Emergiram da análise dos dados cinco categorias - Formação acadêmica; Ocupação principal e remuneração; Motivação; O contato com o público e 'Ser escritor é...' - que são apresentadas a seguir.

\subsection{Formação acadêmica}

A formação acadêmica não é um pré-requisito para o exercício da profissão de escritor. Como é possível perceber no Quadro 2, nenhum dos entrevistados cursou faculdade de Letras. E, apesar de Sofia, Igor e Lucas terem se graduado em cursos relacionados com a escrita, como jornalismo e comunicação social, chama atenção o fato de José - o entrevistado com o maior número de livros publicados, inclusive no exterior - não ter concluído o Ensino Médio. No entanto, observa-se que - à exceção de José - todos possuem ao menos uma graduação, ou seja, são considerados no mercado de trabalho profissionais qualificados.

Quadro 2: Formação acadêmica dos escritores

\begin{tabular}{|l|l|}
\hline Nome & Formação acadêmica \\
\hline Ivan & Graduação em Direito, Administração e Música; curso de cameraman \\
\hline Artur & Graduação em Engenharia; Doutorado em Filosofia; curso de artes dramáticas \\
\hline Caio & Graduação em Publicidade; curso de roteiro e graduação incompleta em Cinema \\
\hline José & Curso secundário incompleto \\
\hline Sofia & Graduação em Jornalismo; curso de roteiro \\
\hline Lucas & Graduação em Comunicação Social \\
\hline Igor & $\begin{array}{l}\text { Graduação em Jornalismo Cultural e Comunicação Social, especializações em } \\
\text { Comunicação e Imagem, graduação incompleta em Ciências Sociais }\end{array}$ \\
\hline Diogo & Graduação em Design Gráfico, Mestrado em llustração \\
\hline
\end{tabular}

Quando questionados sobre a importância da formação acadêmica no exercício de sua atividade artística, os escritores não demonstraram valorizar a educação formal. Para alguns, o 


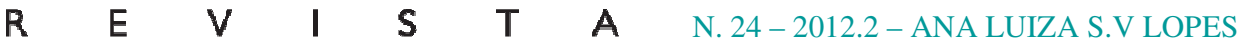

rigor das regras e das técnicas de escrita, valorizadas em formações acadêmicas (Letras, Jornalismo e Comunicação Social) podem atrapalhar a fluidez das palavras, necessária no ato de escrever. Para Igor, por exemplo, "o curso de letras tende a transformar a literatura em aplicação de tese". Ele relata que trabalhou muito tempo com jornalismo e teve que "aprender a ter dois botões, o de escritor e o de jornalista".

No entanto, todos os entrevistados relatam valorizar o estudo, a pesquisa e a atualização constante para a elaboração de suas obras. O depoimento de Lucas ilustra o empenho de um escritor em estudar e pesquisar: "Eu passei 15 anos estudando, tentando resolver algumas questões, tipo 'como é que eu vou escrever sobre operariado, vida de operário e tarara, usando a forma do romance?"”.

\subsection{Ocupação principal e remuneração}

Como é possível ver no Quadro 1, nenhum dos entrevistados se dedica exclusivamente à sua atividade artística. Três possuem um emprego formal em outras ocupações e os outros cinco são autônomos e exercem atividades paralelas à escrita, para garantir sua subsistência. Identificou-se uma variação na percepção desses dois grupos com relação à expectativa de remuneração proveniente da atividade artística.

Os que possuem um emprego formal independem do retorno financeiro de suas criações e não têm expectativa de que essa atividade seja uma verdadeira fonte de remuneração. Há inclusive a consciência de que o exercício da atividade artística ocupa um tempo que poderia ser dedicado a outras atividades melhor remuneradas, os levando assim a ganhar menos dinheiro. O relato de Caio sobre a divisão do seu tempo entre a escrita de romances e o emprego como roteirista de TV ilustra essa ideia: "É, você tem que achar um ponto de equilíbrio. Eu poderia estar ganhando bem mais, eu poderia me dedicar muito mais a escrever roteiros de TV, mas eu não quero".

Entre os autônomos, a questão da remuneração assume maior relevância, pois eles necessitam do retorno financeiro obtido com sua arte - ou com atividades relacionadas a ela para sua subsistência. Esse grupo, que lida com a incerteza de seus ganhos, demonstra preocupação não apenas com as contas do dia a dia, mas também com a (in) segurança financeira no longo prazo. No entanto, apesar das dificuldades relatadas, eles não dão foco 
comercial ao trabalho artístico. A questão da remuneração, apesar de ser relevante, não é o único determinante de suas escolhas: mesmo que seja oferecido um bom retorno financeiro, esses artistas não se submetem a exigências que levem à 'morte criativa', nem conseguem se dedicar extensivamente a atividades que não envolvam o prazer da criação. Todavia, alguns apontam a necessidade de eventualmente se submeter a situações de trabalho que restringem sua criatividade. Mas, apesar dessas concessões pontuais, todos afirmam que não trocariam seu trabalho por um emprego formal em outra atividade e reforçam a existência de remunerações não financeiras, como o prazer obtido na criação em si e no reconhecimento do público, itens abordados nas próximas categorias.

Apesar das duas posturas distintas em relação à remuneração, todos os sujeitos entrevistados afirmam que, se fosse possível, prefeririam viver apenas da atividade artística que escolheram exercer.

\subsection{Motivação}

Identifica-se facilmente na fala de todos os entrevistados que a motivação no exercício da atividade artística é intrínseca. Os criadores falam do prazer obtido na realização da atividade em si e sobre o fato da expressão artística ser uma necessidade em suas vidas proporcionando liberdade, entrega, descoberta, expressão e realização - que, quando não atendida, gera cansaço e desânimo. O depoimento de Caio ilustra essa necessidade de escrever: "Eu acho que, mais do que prazer, eu sinto quase uma obrigação de escrever. Porque se você não escrever, aquilo vai te incomodar. É uma coisa que tem que sair de dentro de você. Você precisa fazer aquilo, é uma necessidade. Entendeu?". E o relato de Artur descreve o prazer com a atividade em si:

Eu deixo de fazer coisas, de sair, porque eu prefiro ficar escrevendo. O essencial é escrever. [...] O romance te possibilita uma viagem absoluta. De criação de mundo, de criação de pessoas... e essa busca, que é inquietante, que você fica batalhando, ela é que é o barato. Então eu sou um escritor que gosto da hora que escrevo. O que eu gosto é desse embate, aqui. Dessa, dessa... [coisa] que tenho que tirar de dentro de mim. [...] Porque essa é a questão do artista, é a questão da criação. 


\subsection{O contato com o público: exposição, publicação e reconhecimento}

Constatou-se que os escritores veem um grande prazer na atividade de criação em si e muitos deles não têm expectativa de retorno financeiro. Logo, a pergunta que surge é: porque tornar sua obra pública? A imagem comum de que o artista, em geral, gosta de exposição é confirmada pelos entrevistados. Nas palavras de Diogo: "Artista é vaidoso, né? É sempre bom”. Mas, além disso, a publicação é vista tanto como conclusão do trabalho, quanto como concretização de uma ideia abstrata no 'mundo real', independentemente do volume de vendas da obra. O relato de Caio sintetiza essa visão:

Para que publicar, para que vender? Eu acho que tem a ver, assim... enquanto o livro está na sua cabeça, ele tá num mundo, é... ele é uma realidade para você, mas não é uma realidade para o mundo. Então acho que você tem a necessidade de que aquilo ali vire uma realidade dentro do mundo das pessoas, do mundo em que você vive. Isso é importante para o escritor. É como se ele tivesse nascendo, a criança nascendo e crescendo, né? Então aquilo ali vai virando uma realidade e acho que você aproveita mais aquilo que você inventou. [...] Mesmo que seu livro não venda muito.

E o que os escritores esperam da reação das pessoas? Eles desejam reconhecimento, no sentido de provocar uma emoção positiva, mas o tipo de expectativa varia de acordo com o grupo ao qual a pessoa pertence. A apreciação das pessoas mais próximas - amigos e familiares - na maioria dos casos é positiva e, por isso mesmo, considerada menos confiável devido "à generosidade que os amigos têm” (Ivan). Já a opinião positiva dos desconhecidos, por ser mais isenta, costuma causar um impacto maior no ego dos escritores. Para Ivan: "uma pessoa que eu não conheço dizer que curtiu o livro, é ótimo."

Em relação à opinião dos críticos, tanto nos meios de comunicação quanto em estudos universitários, a expectativa é de valorização e legitimação da obra, como ilustrado no relato de José: "eu acho que as críticas não têm importância para o leitor, elas têm importância para o autor. Até para dar uma certa legitimidade ao que você fez e pra dar uma certa moral perante o editor, mesmo que não venda, "mas ele é bom, olha só o que a crítica tá dizendo"”.

Os prêmios também são considerados importantes, não apenas para a divulgação do trabalho e para a imagem do artista, mas para a realização pessoal (ego) do autor. 
Outra questão interessante surgida nas entrevistas é a relação entre a apreciação do livro e sua vendagem - duas variáveis não necessariamente relacionadas. Ou seja, há livros que são premiados, recebem críticas excelentes e, no entanto, não são sucessos de venda. Nesse caso, os autores declaram dar mais importância às críticas. Na visão dos escritores, a questão comercial realmente não é a mais importante, pois, apesar de a remuneração ser bem vinda, o reconhecimento é fundamental para a experiência de trabalho desses artistas.

Independentemente de sua origem, uma crítica negativa sempre afeta o artista, mas vale destacar que, muitas vezes, pior do que o comentário em si, é a maneira como ele é feito. Curiosamente, um comentário positivo também pode desagradar, por exemplo, quando um elogio é feito a uma obra da qual o criador não gosta. De qualquer modo, as críticas positivas ou negativas podem exercer influência no trabalho dos criadores. Os artistas declaram que não necessariamente vão concordar com a opinião ouvida e alterar seu trabalho, mas costumam pensar a respeito e consideram a existência de comentários positiva.

\subsection{Ser escritor é...}

A análise dos relatos revelou a visão deste grupo sobre a profissão. Para alguns, ser escritor é estar constantemente envolvido em um processo de autoconhecimento, conforme descrito por Caio: "acho que [ser escritor] é ter um compromisso com conhecer melhor a si mesmo. É um processo de descoberta".

O trabalho criativo foi também associado a uma forma de se comunicar e de se relacionar com as pessoas, tanto por meio das obras lidas ou escritas, quanto pelas interações pessoais que ocorrem durante o processo de trabalho.

A profissão é entendida, ainda, como uma maneira de estabelecer uma relação com o mundo em uma condição de troca, ou seja, de receber e oferecer algo à sociedade por meio da expressão individual e singular do artista - manifestação de uma ideia, de uma opinião ou de uma interpretação. Ou seja, a autoria de um trabalho também é vista como a produção/criação de algo novo no mundo. O relato de Lucas ilustra essa visão:

[...] eu vou buscar na memória coletiva o que eu vou escrever e, portanto, quando eu termino de escrever um livro, contando a estória à minha maneira, eu devolvo isso pra memória coletiva. É o que vai realimentar essa memória coletiva, então na verdade você faz uma intermediação. 
Por fim, observou-se no relato de todos os entrevistados que a definição de 'ser escritor' não é vista como um trabalho (no sentido de emprego), mas como: (i) uma atividade produtiva que permite a expressão da individualidade; (ii) uma forma de se relacionar consigo próprio, com outras pessoas e com a sociedade, e (iii), um modo de ser no mundo.

\section{Discussão dos Resultados}

Na revisão de literatura, Menger (2010) aponta que há uma dificuldade na definição das profissões artísticas, dando origem a uma pluralidade de critérios que visam reconhecer sua legitimidade, entre eles, a qualificação profissional - diplomas de escolas de arte. No entanto, constatou-se na pesquisa de campo que a formação acadêmica não é vista como um prérequisito para o exercício da profissão de escritor: nenhum dos entrevistados cursou faculdade de Letras. Contudo, apesar de nenhum deles considerar a educação formal como essencial para a prática da atividade artística, todos valorizam o estudo e a atualização constante, seja da maneira que for. Observa-se, ainda, que a maioria dos entrevistados possui ao menos uma graduação, ou seja, são considerados no mercado de trabalho profissionais qualificados.

Em relação à ocupação principal, nenhum dos entrevistados se dedica exclusivamente à sua atividade artística, o que está de acordo com as indicações de Hesmondhalgh e Baker (2010) de que no trabalho artístico há predominância de trabalhadores independentes que tendem a se dividir em vários trabalhos. Em relação à remuneração, os que possuem um emprego formal em outras ocupações não têm expectativa de ganho com a atividade artística, mas os autônomos demonstram preocupação com sua (in) segurança financeira, confirmando a afirmação de Greffe (2010), de que muitos artistas rejeitam a imagem de indiferença em relação ao dinheiro.

No entanto, apesar da questão da remuneração ser relevante, não é o único determinante de suas escolhas, pois, mesmo havendo uma boa proposta financeira, os escritores declaram que não se submetem a exigências que tolham sua criatividade, nem conseguem se dedicar extensivamente a atividades que não envolvam o prazer da criação. Todos os entrevistados, mesmo os com emprego fixo, afirmam que, se fosse possível, prefeririam viver apenas da atividade artística. 
A busca por um equilíbrio entre renda e atividade criativa, identificada neste estudo, corrobora a afirmação de Throsby (2007) sobre a divisão do tempo total de trabalho dos artistas em trabalho criativo, trabalho artístico e trabalho não artístico.

Os entrevistados confirmam que a motivação mais importante para o seu trabalho é a satisfação pessoal com a criação, enquanto atender às necessidades práticas, como agradar um cliente ou pagar as contas, é uma questão secundária (ELSBACH, 2009). Tanto a literatura acadêmica em Administração quanto a pesquisa de campo deixam clara a existência de uma forte motivação intrínseca no exercício da atividade artística.

Ratificando as afirmações de Menger (2010) de que o artista considera a criação como elemento essencial de sua vida e busca uma satisfação intrínseca no exercício de sua profissão, os entrevistados falam sobre a necessidade da expressão artística em suas vidas e sobre o prazer obtido no trabalho.

Os resultados da pesquisa também confirmam a percepção apontada na revisão de literatura de que os artistas veem a exposição de seu trabalho como uma dimensão essencial de sua identidade, pois é a demonstração de que sua arte é legítima e valorizada pela sociedade em geral (ELSBACH, 2009). Porém, adicionalmente, este estudo identificou que a publicação - principal forma de exposição do trabalho dos escritores - também é vista como a conclusão da obra e a concretização de suas ideias abstratas no 'mundo real'.

Entre a pluralidade de critérios que visam reconhecer a legitimidade da profissão artística, Menger (2010) destaca o de 'ser considerado como artista, tanto pelo público quanto pelos outros artistas'. Nessa linha, a análise dos dados aponta que os escritores desejam reconhecimento do público e dos críticos. Enquanto a apreciação do público traz satisfação pessoal, os prêmios e a opinião dos críticos, além da satisfação, são considerados importantes para a valorização e legitimação da obra. Vale destacar que o sucesso comercial (volume de vendas) não é considerado um indicador importante de reconhecimento ou legitimação, reforçando o papel secundário da questão econômica na atividade profissional desses artistas.

Conforme abordado por Menger (2010), identificou-se, no presente estudo, que 'ser escritor' é uma forma de contribuir com uma interpretação singular para o desenvolvimento da arte e da cultura, sendo esta atividade relacionada ou não a um vínculo empregatício. E, ainda, em concordância com o que foi apontado por McGuigan (2010), identificou-se, na 
análise dos dados, que a prática da atividade artística representa a realização de um trabalho não alienado.

No entanto, adicionalmente, a presente pesquisa identificou que os entrevistados definem o 'ser escritor', não como um emprego, mas como uma atividade produtiva, nem sempre remunerada, que permite um modo singular de relação com o 'mundo' e uma vida repleta de sentido.

\section{Considerações Finais}

Os resultados deste estudo sugerem que, para o grupo analisado,

- $\quad$ a formação acadêmica específica na área de atuação não é relevante para o exercício da atividade artística;

- a renda obtida com a atividade artística não é, na maioria dos casos, o suficiente para o sustento do indivíduo;

- $\quad$ a motivação no exercício da atividade artística é intrínseca;

- a questão comercial e financeira não é a mais importante para os artistas: a remuneração é bem vinda, mas o reconhecimento é fundamental.

Vale lembrar que a pesquisa de campo se baseou no mercado editorial no Brasil e, desse modo, um ponto fundamental a ser observado é a especificidade dos indivíduos selecionados: é preciso ter em mente que as conclusões do estudo não devem ser automaticamente estendidas a grupos com características diferentes, como artistas de outros países ou setores. Apesar dessa restrição, as conclusões podem ser úteis para outros trabalhadores que possuam características semelhantes. Por exemplo, o perfil estudado parece semelhante ao de outros criadores, como pintores e escultores.

Pesquisas futuras podem investigar outros perfis de trabalhadores criativos, sendo interessante destacar dois tipos bem diferentes dos estudados: os que exercem a criação em grupo, como nas companhias de teatro ou cinema; e os empregados em firmas, como agências de publicidade. 


\section{Referências bibliográficas:}

BARDIN, Laurence. Análise de conteúdo. 3. ed. Lisboa: Edições 70, 2004.

BENDASSOLLI, Pedro F.; WOOD JR., Thomaz; KIRSCHBAUM, Charles; CUNHA, Miguel Pina e. Indústrias criativas: definição, limites e possibilidades. Revista de Administração de Empresas, v. 49, n. 1, São Paulo, jan.-mar. 2009, p. 10-18.

CRESWELL, J. W. Research Design: Qualitative, quantitative and mixed methods approaches. Thousand Oaks, CA: Sage, 2003.

ELSBACH, Kimberly D. Identity affirmation through 'signature style': a study of toy car designers. Human Relations, v. 62, n. 7, jul. 2009, p. 1041-1072.

FLEW, Terry; CUNNINGHAM, Stuart. Creative Industries After the First Decade of Debate. The Information Society, v. 26, n. 2, p. 1-11, 2010.

GREFFE, Xavier. Introduction: l'économie de la culture est-elle particulière? Revue d'économie politique, v. 120, n. 1, jan. fév. 2010, p. 1-34.

GUBA, E. The paradigm dialog. Newbury Park, CA: Sage, 1990.

HARVEY, D. Condição pós-moderna: uma pesquisa sobre as origens da mudança cultural. São Paulo: Edições Loyola, 1992.

HESMONDHALGH, David; BAKER, Sarah. 'A very complicated version of freedom': conditions and experiences of creative labour in three cultural industries. Poetics, v. 38, n. 1, feb. 2010, p. 4-20.

LAMPEL, Joseph; LANT, Theresa; SHAMSIE, Jamal. Equilíbrio em cena: o que aprender com as práticas organizacionais das indústrias culturais. ERA: Revista de Administração de Empresas, v. 49, n. 1, jan.-mar. 2009, p. 19-26.

McGUIGAN, Jim. Creative Labour, cultural work and individualization. International Journal of Cultural Policy, v. 16, n. 3, aug. 2010, p. 323-335.

MENGER, Pierre-Michel. Les artistes en quantités. Ce que sociologues et économistes s'apprennent sur le travail et les professions artistiques. Revue d'économie politique, v. 120, n. 1, jan.-fév. 2010, p. 205-236.

POTTS, Jason; CUNNINGHAM, Stuart. Four models of the creative industries. Revue d'économie politique, v. 120, n. 1, jan.-fév. 2010, p. 163-180.

TEPPER, Steven Jay. Creative Assets and the Changing Economy. The Journal of Arts Management, Law, and Society, v. 32, n. 2, Summer 2002, p. 159-168. 


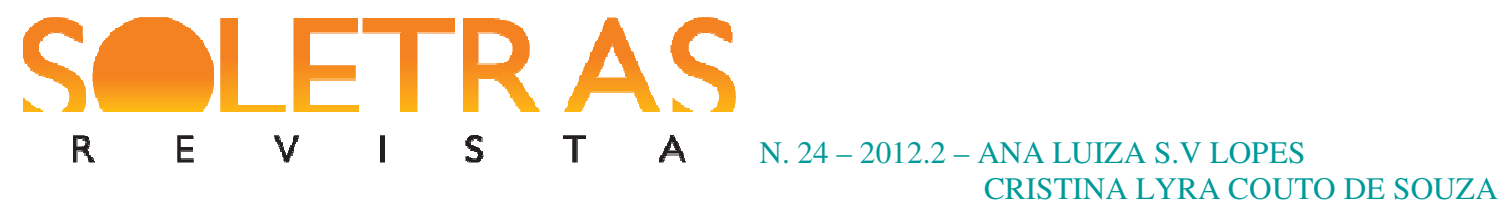

THROSBY, David. Preferred work patterns of creative artists. Journal of economics and finance, v.31, n.3, Fall 2007, p. 395-402.

TOWNLEY, Barbara; BEECH, Nic; MC KINLAY, Alan. Managing in the creative industries: Managing the motley crew. Human Relations, v. 62, n. 7, jul. 2009, p. 939-962.

\title{
Work and Literature: the perceptions of a group of Brazilian writers
}

\begin{abstract}
The growing economic and social importance of the creative industries - activities in which creativity is the essence of the business, covering the cultural and artistic production - is not yet reflected in the generation of studies on their managerial and organizational issues. Therefore, the authors of this article have been engaged in researching about creative industries from the perspective of its main actors - the creative people and the managers seeking to understand how they work, what they want, how they interact to each other and with the market and what difficulties they face. This study is part of this line of investigation and aimed at describing the perceptions of a group of Brazilian writers. A qualitative research was conducted, based on interviews with Brazilian writers. The results suggest that although the specific academic training in the field is not necessary for the performance of the work activities, respondents value the constant intellectual improvement through study and research; they perform many parallel activities to the artwork - needed for sustenance - but if it was possible, they would prefer to earn a living from literature, even if that means getting lower income; the need for publication goes beyond the expected financial return: it is seen as the completion of the work, regardless the sales; writers have an intrinsic motivation linked to the performance of the artistic activity in itself - for many, besides the satisfaction, the artwork is a necessity.
\end{abstract}

Key words: Writers. Artistic work. Creative work. Creative industries. Business Administration.

Recebido em: 16 de dezembro de 2012

Aprovado em: 12 de janeiro de 2013. 